\title{
Disruptive Education for Sustainable Development-Cultivating Positive Learning Dispositions
}

\author{
S. Rajeswari ${ }^{*}$, Gyanabati. Khuraijam ${ }^{2}$ \\ ${ }^{1}$ Humanities \& Sciences Department, Gokaraju Rangaraju Institute of Engineering \& Technology, Hyderabad, India \\ ${ }^{2}$ Management Humanities \& Social Sciences Department, NIT Agartala, Tripura, India
}

\begin{abstract}
Education is the process through which sustainable development can be achieved. Learners develop values and skills through proper guidance individually and collectively that enable to improve the quality of life. This paper addresses how teachers need to continually interrogate their practices focusing on improving outcomes of learners. Positive behaviour supports student learning and development in achieving their desired objectives. The methods involve dispositions, the key components for one's sustainable development. The results suggest that environment with supportive autonomy versus controlling is essential for sustainability. Teachers need to cultivate appropriate positive dispositions in terms of interest, inventiveness and intensiveness. To elevate learning capacity, teachers provide challenging and appealing environments to extend student capabilities thus heightens their efficacy. Rendering the focus on research as eminently topical and pertinent which adds an importance to the existing literature through the direct focus into the classroom space with digital devices where disruption takes place.
\end{abstract}

\section{Introduction:}

The paper figures the special needs of students to achieve disruptive education for sustainable development. Learners' dispositions seemed to be the most obvious direction to explore. Teachers need to cultivate appropriate dispositions for students with special needs and the ability to make choice in terms of interest, inventiveness, intensiveness, persistence, optimism, reciprocity, resilience, selfmotivation, liberty, critical thinking and risk taking. To achieve a smart, sustainable and inclusive education, technology plays an important role in facilitating the required needs. Teaching is a process of helping students towards desirable outcomes by giving a comfortable space to learners to interact.

The urge to start this project was on the premise of marvellous keynote address by Guy Claxton, 2006 about "expanding the capacity to learn" [1]. Education should aim providing valuable and effective source to students by improving their potentials giving a precious end. It is important to find the ways to convert the good aims into achievable goals is the hour of urgency. The present world presents everyone with intense level of challenges and individual responsibility. Especially young people are not able to cope up even with general challenges. Almost every day brings a new report on young people's escapism, anxiety and depression that leads to harm their self and also suicidal thoughts. Expanding learning capacity is a vital and timely goal of the present education. Every student need to be educated for their future. To raise the graph of standard is to improve results. The results are found good only when teacher teach learners how to learn instead of teaching knowledge. As such, it is through this education the basic job expansion of young people's intellectual and emotional resources to cope up in life helping youngsters extend their capacity to face challenges capably with confidence. It is also important to have the efficiency to organise and evaluate one's learning.

Another important issue is that autonomous learning is a part of skill. At this point the important traits like values, attitudes, emotional tolerances, dispositions and brain function plays a vital role. The necessary challenges need to be updated only with valued characteristic features. These features should potentially cultivate learning dispositions positively to acquire on regular update basis. For this instructors should give space for a degree of encouragement and support to the learners. Positive learning dispositions provide opportunities for students to expand their self-regulated learning capacities. Computer resourced classrooms with 
complete monitoring and guiding influences working practices to foster independent learning. This leads to creation of peer learning cultures opening the doors of critical thinking. Assessment on dispositions includes questionnaires, focussed group questions, attitude scales, selfreport inventories and observations. The areas of operation need to be selected, framed and designed to deliberately focus on improving learning capacity. Implementing the learning spirit was difficult to achieve. Thus, as a primary step, an extensive literature review was done focusing on learning autonomy and education for sustainable development.

\section{Literature Review}

Many studies have been made on learning disruptive innovative technologies and its implications in higher education. A challenge for instructors is to observe always and recognise innovation that might be a disruption. In the process of upgrading the quality chain, Christensen, [2] says "losing touch with the mainstream". But the disruptive innovation theory has remarkable descriptive power in learning through challenges and alterations defy higher education. Thus, the primary aim of the present study is disruptive education for sustainable development.

The present life demands new outcomes for students. They need to continuously mastery new knowledge and skills because of heavy competition for their career success. The change requires investment of voluntary energy of an individual as each take great comfort in one's routines. Educators must first help education systems begin to shift over from low-value uses of learning tools to high-value uses. The forward steps require ending of old practices and demand tentative steps toward implementing new ones. Besides successfully introducing, disruptive innovation is also defined as changes in the way of life we live and social practices offering multiple opportunities for "new profit growth" [3].

Studies have been made on available literature extensively to examine external and internal impeding factors that improve a conceptual framework of the capabilities. The understanding factors are limited and practical insights should be clustered to bridge the gap for a better understanding. The essential insights need to facilitate the improvement of various competencies and mind sets that develop the competencies. In this uncertain world learning dispositions are key to competitive advantages. To step out of our comfortable zones willingly, we must cultivate certain learning dispositions.
In the previous works of Carr et al. [4] argued that $21^{\text {st }}$ century education aims at developing confident and skilful abilities to face all types of perplexity. Like Perkins Jay \& Tishman Carr et al. articulated goals as a combination learning inclinations and skills. They described them as ready, able and willing to involve a productive learning. Such characteristics are labelled as "dispositions" $[5,6]$.

As Costa [7] defines them as "habits of mind". All the definitions specified the prominence with a degree of clarity that helps educators to identify learners' goals. Learning curriculum which is designed by the respective educational institutions can steer learners towards developing attributes. This paper analyses also enriches the learning theories. The learning dispositions are positive increasing the capacity of acquiring effective skills. The development might be in various domains that they appear. The present study is an attempt to elevate the learning capacity of the students through positive dispositions. The purpose of this study is to investigate how learners acquire right skills in productive learning environments for disruptive education.

Positive behaviour supports by cultivating students learning and development in achieving their desired objectives. Therefore, motivation, learners' attitudes and attributes overcoming challenges showing the possible solutions were addressed in the present study.

\section{Methodologies}

This paper focuses on disruptive education and its importance in education teaching and learning. The contemporary approach is to examine learning dispositions and investigate the possibilities for sustainable development. The study is based on an extensive review of available literature and examines the possible positive learning capabilities for students to achieve productive output.

\subsection{Elevating learning capacity}

Able to make appropriate response to the context is the skill and take away of learners from the educational institutions. Teachers need to educate pupil the core function "learning to learn" [1] for life time how to perform in unknown situations. If the learning capability of an individual gets elevated and learners flourish in a diverse world. Students can examine available information that helps to develop generic capacity in learning. The instructor need to find ways for valid and goal oriented education by unpacking the notion of learning. The learning capability building environment expands student's capacity to learn providing opportunities to selfregulate their practices. The balance in responsibility fluctuates based on efficacy and 
capabilities of the learners. New learning can help to build value based culture with sustainable development that contribute to welfare of the society. Engaging students providing them opportunities to learn develops new competencies which play an important role in education. Such competencies help the learners suggest a lifelong learning. They are likely to be energised providing the skills to grow within their desired path. The skills are to be updated as per the exiting job opportunities. Corporate learning need to undergo revolutionary changes with "constant technological advances" [8] to enhance company culture and live with values.

Learning should align with overall priorities. A deliberate and systematic approach is necessary for a capability assessment based on a specific strategic direction. Teachers play a key role to improve student's achievement largely on expectations of the educational institutions. This can be done by mobilising the talents of teaching staff of an institution. Instructors play a decisive role in initiating to enhance students learning outcomes. Leithwood [9] have researched that creating a genial climate to educate cultivates leadership qualities in learners. Forming teams also help teachers to observe and monitor learning and give feedback on standardised tests at regular intervals both individual and group enhances learner's performance. The strategy should focus on operational aspects to keep a track record of the progress. In this method teachers need to identify, diagnose and intervene learner's difficulties or of their advanced skills. It epitomizes collaborative curriculum and pedagogical work that the instructors adopt to do allowing each learner to move forward and providing appropriate inputs.

\subsection{Teachers autonomy}

Autonomy is considered to be a human trait being aware of the strategies having "greater control" [10] over one's learning. The instructors need to build the capacity to engage in self-regulated and self-directed teaching. With mutual cooperation an autonomous teacher gains and acquire knowledge, attitudes and skills required to exercise the right thing.

Features of autonomous teacher are discussed as hereunder:

\subsubsection{Self-regulated action}

Self-regulated action refers to an active constructive process driven by one's actions, feelings and thoughts towards "personal goals" [11]. The value has been extensively associated with academic performance to meet social competence. Teachers play a vital role in shaping their students emotional behaviours and cognitive thinking. The action helps them to tailor teaching engaging in self-assessment and professional discussions. It may vary depending on conceptualisation of various theories. The crucial issue challenging all theories is to understand and analyse how these capabilities are chosen to changing situations. Shouldering the learning responsibility is the fundamental aspect for selfregulated learning.

\subsubsection{Self-directed action}

The significant characteristic feature of autonomous teacher is "Self-directed action" [12]. Self-directed action of teacher has an impact on educational system and teacher development. Educational system examines instructor's roles in sharing their knowledge and learning by directing, initiating and sustaining their approaches. The approaches should align planning and implementing their instructional materials. Teacher mentors help and support selfdirected actions of an individual. Awareness of issues by teachers with sentient control make them opt and act aptly results in one's ability. This may lead to professional development of a teacher.

\subsubsection{Self-regulated professional development}

Teachers' professional development along with emerging changes produce effective approaches and models for designing high-quality education. Identifying contextual factors that support to improve teaching -learning are more likely to be effective method to sustain and be intensive. The teachers need to focus on instructional plan of the curriculum of an educational institute. Reformation of efforts tailored to teachers goals for the learners output and multiple experiences help to direct an apt teaching plan.

\subsubsection{Adoption and successful application of knowledge}

Successful application of teacher's knowledge can be based on environmental factors of an organisation driving to knowledge adoption. To obtain competitive benefit the acquired knowledge can be used and it acts as an asset for an individual and organisation as well. It is a systematic process to collect, select and utilize effectively to finish the assigned tasks to achieve organisational goals. Organisational support in the form of policies and procedures with required infrastructure influence application of knowledge. A teacher need to investigate the driving factors for successful implementation.

\subsubsection{Right attitude}

Teachers are nation builders. Progress of a country depends on the qualified attitude of its teachers. An effective teacher can make positive differences on the lives of their learners. Attitudes and actions 
applied by the instructors with genuine caring and willingness to share knowledge with sincere sensitivity effects student's motivational levels providing them meaningful learning experiences. Effective attitudes of teachers and students develop good relations with mutual trust and respect. Attitude of teachers effect students learning in many ways shaping their learning experience. Prospective teachers need to inculcate healthy attitudes improving their skills and knowledge to compete their teaching. As such proper training should be provided by the organisations to secure the right teacher. Education system can flourish with constant updating and refinement of skills of serving teachers. The tendency to react to value education shapes up a qualified teacher. Positive attitudes promote learning and create an environment that stimulates efficient and effective learning. Thus teaching becomes a dynamic activity that leads to holistic development of the society. An active teacher with humanistic approach brings experiences, ideas and beliefs to the classroom with the purpose of fulfilment. Clear set of objectives are maintained in the process.

\subsection{Learners Autonomy}

Interaction between teachers and learners is critically important in education. Learners' autonomy need to understand by the teacher to adapt them to the classroom learning. The learner's autonomy can be acceptance of responsibility of individual learning. The techniques for self-learning with proper understanding is required to regulate the autonomous learning. In the process, the learner holds independent action as a result of the capacity for detachment. And also gains knowledge to set goals, choose purpose independently, set tasks and pick criteria for evaluation.

Features of autonomous learners are discussed as hereunder:

\subsubsection{Self-awareness}

Self-focused study leads to success. It helps to obtain the desired goals. Autonomous learners choose the right path that best fits their skill-set. Instant occurrences in self-awareness can be assessed by the help of "Situational Self-Awareness Scale" [13]. Self-awareness also connects to the ability to engage one's mind which constitutes a "fundamental component of social cognition" [14]. It refers to the capability of becoming an object of “one's attention towards self'[15]. Such individual can actively identifies and processes information and stores it about the self. The experience of perceiving and processing stimuli make a person self-aware of the things. Such awareness represents a multidimensional phenomenon which comprises of various corollaries and self-domains. Genuine curiosity about self in which one is interested in knowing and learning about values and attitudes present positive results in good mental health.

\subsubsection{Curiosity to learn}

Curiosity has a great potential to intensify learning. Inquiry based learning method acts as a potential mode of stimulating student's curiosity. This can also be used as class room technique which could be applied to any academic discipline. It acts as a guiding principle of teaching in education contexts motivating students.

\subsubsection{Well disciplined}

"Classroom disruption" [16] is the major challenge endured by teachers. To achieve instructional goals teachers, consume "a great deal of energy" [17-19] towards classroom disruption. Students who have been disciplined in a proper, positive and respectable ways become secured and competent independent people. It also enhances learner's self-esteem. Teachers need to provide natural consequences that a student can understand. This happens with natural experiences from mistakes. As such learning process becomes more effective and attractive. Knowledge acquisition in a well self-disciplined process could be considered as a prominent factor to improve one's learning outcome. To achieve self-goals, dedication to self-discipline is advisable with good motivational instruments.

\subsubsection{Motivational}

Motivation is an influential factor in teachinglearning process. It reflects learner's choices in learning tasks. Students understanding the importance of learning and developing interest prefer to work independently. Students possessing such a good quality initiate the task, diligence in learning, punctual and well-disciplined and always tries to learn for the best results. Motivated students take responsibility in learning and engage themselves academically to achieve their self-goals. Motivation could be considered as a key to success.

\subsubsection{Independent learning}

Independent learning ensures students ability to engage themselves in learning. Learners need to break the activities into smaller and manageable tasks to meet the challenges that come across. Flexible time limits can be set for completion of the desired attentions. To meet thee learning outcomes independent learners finds the required information effectively and evaluates the process critically. 


\subsubsection{Skilled in evaluating}

Self-evaluation can promote essential motivation, mastery in goal setting with internally controlled attempts leading to meaningful learning. In this method learners also can monitor in evaluating the quality of thinking when learning. They could identify the strategies to improve their understanding. Students with self-evaluation skills are able to "persist on difficult tasks" [20]. This helps them be more confident in completing their responsible works. Teachers have to provide opportunities for learners to mastery the concept of evaluation in a controlled manner of their performance. They could get the possibility to check their progress at regular intervals while immersing themselves in the tasks. Such mechanism enhances learning in a meaningful manner and identify further essentials of the work. Students' involvement in assessing work gives them freedom of choice in a more responsible specific direction. In this process students need brainstorm their ideas and negotiate with the instructors to arrive at final decisions. These steps would surely improve student's self-efficacy securing high scores of accountability tests.

\subsubsection{Self-reinforcement}

Learners and teachers work together in the process of learning. As a result both learner autonomy and teacher autonomy interact with each other. At this juncture the instructor plays an important role in engaging students in autonomous and effective learning. Proper guidance must be checked by the teacher. Brodsky "personal heritage" limitations can be transcended by individual learning capability. The autonomy implies freedom from self. Motivation and attitude represent the foundation of learning. Increasing technology improves the learning environment of the students. This would be considered as an effective source to build network and confidence for sustainable development in teaching -learning process.

\subsection{Research based classroom}

Adopting a new style of learning became a necessity now-a-days. A well organised class helps instructors sustain good relationships with their learners. Exploitation of learning possibilities can be through facilitating the resources. The autonomous learners realise the importance and purpose of learning. The instructor need to share the objectives of the course with clarity which leads to accountability. Teachers' structural preparation plays a key role to create research based classroom. This helps the learners to switch from known to unknown figuring out the contextual meaning. Teachers and students gain knowledge and experience from their practices. As such teaching-learning process becomes productive. Engaging learners at different individual levels yields proactive learning. Teachers always keep their classroom free from disruption. To retain positive behaviour it is necessary to correct the learners in a passionate way that motivates their innovative learning. The instructor plans and organises activities to promote learners research based environment. Many of the beginning teachers do not comprehend the importance of classroom management techniques effectively. To gain knowledge for appropriate instructive methods teachers need to attend training sessions to upgrade their skills. Learners' new ideas are one of the key factors to determine teachers approach to streamline research based classrooms. "Determining the way" [21] the learners think of their teachers organising skills of the class is of great importance to have a positive learning.

A series of activities create a vehicle to judge learner's goals and are bound to do well. This mirrors an action oriented approach. "Informative feedback" [22] helps learners develop mastery over performance. Teachers play a very important role in education domain as they build teaching-learning process interesting. Mastering material is the successful method. And also maintain and restore teacher-student relationship is important. As such learners feel and experience a greater sense of belonging. The classroom need to be arranged providing frequently used teaching material and student materials readily and easily accessible.

\subsubsection{Classroom-Centered Research}

Teaching profession might make important changes in contemporary world. Teachers' education is considered as one of the closely connected research transfer that might bring the changes. In the light of paradigm shift of education that is based on constructivism which is considered as knowledge users defining position as knowledge makers. The research is an effort to earn perception into what accounts for an effective teaching. Instructors should be able to implement their teaching plan and observe by monitoring the effects of teachinglearning process that bring change in classroom. It also acts as a tool for effective professional development. Thus teacher becomes more aware of classroom learning environment. This awareness empowers to become more effective decision maker of what goes on in the classroom for a successful teacher.

Inquiry and research based activities are to be practiced to improve research competencies of professionals in teaching field. Learners should be involved in teaching-learning process where theory and practice emerge and interconnect with each 
other. In this method learners need theoretical orientation courses to work on skills. Observation and interpretation skills develop by the process. When involving in practice sessions "reciprocal interaction" [23] plays a vital role. The method not only produces researchers but also provide students with sufficient skills with sufficient knowledge through which they are capable of applying knowledge. To achieve this the instructors need to continue their life-long learning to create positive favourable climate stimulating towards researchbased approach in teaching and learning. Such use of classroom centred research helps to propose to access research through classification of factors that help education practitioners.

\subsubsection{Research-based practice}

Teachers' instructional practices are considered to be effective in education as they provide improved learners outcomes. They also influence meaningful effectiveness that are determined for definite groups of students. This can also act as foundational assumption for modern education practices and give teaching a positive impact on students' future. Being aware of research, the primary focus should be on methods and strategies education practitioners apply to access research. Such practices might include nature of research, form of research evidence and the practitioners and their background, interests and needs. "Educators benefit" [24-27] from understanding various related works like how, why, where and when it can be applied. This could be found as effective ways of engagement, appropriate pacing and monitoring learners' performance leading to students' achievements. The method might not give scope for "absence of professional judgment" [28]. Nature of research has to overcome the form of utilisation barriers. The gap plays a primary role in education. Hence, effective educational practices to be made in classrooms for encouraging student output. Implementing the most effective educational practices in curriculum could be a precondition for developing students' achievement meeting the required performance standards. For the process of bridging the research gap, instructors need to focus identifying and implementing research-based approaches in classrooms yields reliable improved student outcomes. Here educators perform remarkable cynicism in applying research practice. This systematic approach determines sufficient studies which are of high quality with appropriate research designs that allows effective assessment to demonstrate meaningful and effective practices. The advantages are sustained with pupils' responses and high motivation in regard to subject performance. The performers become self-confident in accepting the risks and willingness to make changes in understanding and implementing. This provides a reliable estimation and its impact of general practice.

\subsubsection{Technology based learning}

Technology has made a successful way to the educational institutions as a way of result oriented learning. Teaching educational authorities made learning apps which has easy accessibility. The teaching-learning world has undergone massive changes with advanced technology that has developed separate teacher edition and student edition. As a start with technology based learning "e-learning methods" [29] can be adopted at the beginning stage. A blended e-learning method can be adopted where interactions are required in the classrooms. This method helps the learners to gain background knowledge of the topics under discussion.

Self-study method providing all the details of website and login credentials stimulates the interest of the learners to complete the online assignments successfully. The instructors availably helps the students to solve the problems they come across either with the learning material or the website itself. Mobile learning is also one of the good methods giving the way to more possibilities of effective learning where portability and affordability of the devices happen with good internet connectivity. This could bring a revolutionary change in learner's perspective. The effective features of the mobile technology can be creatively used to make learning acquire high results. The learners are encouraged to add the mobile technology to make learning more efficient by preparing plans.

"Gamification" [29] is an effective tool for young learners that help to supplement their knowledge and skills keeping them entertained all the time. Social interactivity collaborating with other people, participating in discussion forums, creating and writing blogs increase significant quality learning capabilities. The learners also can be asked to make audio recordings and create videos what they had researched and share with other peer group members. At this point, there is a need to check effectiveness and efficiency of using technology. The powerful and effective feature of the technology can be used creatively making learning effective to yield high results.

\subsubsection{Cognitive obstruction}

Modern psychological approach to learn is based on cognitive and behavioural theories. Behaviour consider learning as a process of expecting achieved goals by responses. Behaviourists believe the responses of the learners are automatic but not as a 
result of any other deliberate thought. Cognitive theory says each learner has a definite cognitive structure into which a new learning is absorbed. This is considered as a meaningful process as cognitive interpretation rests upon psychological base of the thought. Also validates experiential learning as the learners understand new input and connect with previous experiences and knowledge. Self-efficacy can also be improved by various learning strategies. Regular note making, analysing, deductive and inductive reasoning, guessing and rearranging the available information can be considered to be cognitive strategies. Learners may choose the learning style that best suits them. Obstruction occurs if goals are not clear. The instructor has a vital role to play in the learner-centred teaching. Learners need to be given more opportunities for learning a specific topic taking more time which gives opportunities for experiential environments yielding learning while doing creating immense possibilities to learn. Each learning task should be based on distinct teaching strategy. Clayton Christensen capsuled "Disruption is a positive force". This force is a process by which new knowledge transforms complicated into simple, convenient and accessible features of learning.

\section{Findings}

\section{Positive dispositions}

The term disposition is "imprecise" (Guy Claxton) focusing on human attributes. Dispositions are coined as habits of mind and respond to situations in definite ways. Positive learning dispositions are patience, being active listener, amicable and curious to learn, responsible, creativity, adaptability, attentive, accepting risks and enthusiastic to learn. Learners' skills, knowledge and attitudes are considered as dispositions even. These dispositions help and support learners' development.

\subsection{Curiosity}

Curiosity is a facet of inherent motivation that has a latent quality to enhance student learning. It is "measured as a trait" [30] that is closely linked to intelligence. It also functions as a disposition to inquire and investigate knowledge. In this method the instructor helps the learners to learn for themselves rather than sharing knowledge. The task in hand of the students is studied by themselves and find out methods to get results are determined by the students. As such knowledge of learners is built in an assembled fashion with constructive ideas and learning proceeds to its best. The observations might suggest that learning curiosity increases motivation that links to theories which leads to deep learning. Providing gaps in theory is also one of the methods where students actively inquire into subjects to resolve their curiosity. Such academic research merge well with curricular approaches in teachinglearning. As such, different educational approaches emphasise on students finding problems and solutions for the problems through investigation methods.

Curiosity is also observed as one of the significant component of human development. It helps to fill the information gap providing the desired knowledge. Abilities to think is possible through active and willing inquire towards change and selfdevelopment. Without such curiosity one cannot adapt and learn complex situations. Curiosity may be connected to creativity that plays a vital role in education domain. Cultivating curiosity in students may be considered as disposition rather than static state. Learners connecting to any specific environment determines to what extent they be curious to shape their learning. Such characteristic feature may also relate to other important dispositions that includes mindfulness, tolerance and innovation.

\subsection{Responsibility}

Students shouldering responsibility for learning has been formulated as one of the important attributes. The attribute develops through competence. Such competence levels help students to set goals and choose their own methods in achieving them. Proper planning help to structure their learning taking control over the process with essential responsibilities. The responsibilities refer to students' abilities to learn academic subjects. In this method responsibility could be a mutual process between student and teacher. Education institutions must pay greater attention in designing the curriculum and instructional materials for developing ownership skills in learning. If the learners fail to grasp the content, teachers need to try to reteach it in a more understandable way. At this point educators build the mind-set of students to take advantage in learning and grab opportunities to learn.

Students with appreciable sense of belonging invest high in learning process. Flipped class could enhance learning of which they watch screencast videos and gain opportunities to re-vies lectures out of class that finds to be a challenging task. This method encourages individual self-regulation more than a typical lecture where there are chances to comprehend the lecture in their own pace. Thus, students and teachers share responsibility of learning and understand the content more deeply that provides greater autonomy in a variety of accomplishments. Educators who teach and promote skills of academic mind-sets help learners thrive in educational institutions. 


\subsection{Creativity}

Educational practices teach creativity. Innovative thinking enables learners to apply their new thought in experimenting alternatives. A productive environment nurtures mind-set of learners. Instructor's motivation plays a vital role in encouraging their significant collaboration. For this learning space should be provided designing cost effective technologies that can stimulate active learning spaces. Active learning might require geographical maps, drawings by peer group members, sketches, images, etc. that set their abilities. Learners feel comfortable sharing their novel ideas that leads to positive learning atmosphere in regard to theoretical contexts. Such practices need to be structured connecting theory and practice. The instructor plays an important role in promoting the practical efforts and abilities engaging them completely within classroom practices in a more comfortable zone. Teachers need to adapt creative solutions that fit the framework. The educators also need to allow space for mistakes to happen where the learner's innovative solutions can emerge. This strengthens multiple intelligences representing extensive diversities.

\subsection{Adaptability}

Defining feature of teaching involves novelty and change regularly. Able to respond effectively can be termed as adaptability. Conceptualised adaptability proposes lifespan development. Individual capacity play an effective role in the process of "environmental opportunities and constrains" [31]. Though related, adaptability differs from cognate process like "coping and resilience" [32]. They observed adaptability of students in academic levity has been termed as "everyday resilience" and also refers to the learner's ability to handle academic challenges and setbacks. The outcomes may show variation in educational well-being that involves protective factors and risks. An individual learner's accommodations that enables adjustments to inherent changings. Adaptability is also relevant to teachers who involves in responding to students managing constant changes. The capacity to adapt teaching works managing appropriate changes is crucial for teachers. Their adaption associates with various factors for healthy and effective functioning of work along with student's outcomes. Selfassessment might help teachers to promote adaptability that leads to professional growth.

\subsection{Enthusiastic}

Teaching is the most important noble profession as it shapes the soul of a child. Human evolution depends on the effect of education and the efforts made by educators. Modern education system focuses on student's role and position in self- learning that occurs through research and creation that demands continuing education. Workshops and student development programs help teachers adopt more real world focus in their respective class environment. Interactive methods of teaching emphasize formative education proving opportunities to assess theoretical knowledge that is in practice and develop personality traits. The methods stimulate individual efforts and discovery of one's capabilities in learning process. Working in pairs and forming groups help students to apply and synthesise the acquired knowledge in varied and complex methods. This facilitates learners to learn more thoroughly than learning individually. The group futures a sense of trust, safety, encouraging mutual training and learning leading to disappearances of fear of failure, minimising emotional blockages. It is a challenging task for the teachers to manage stimulating the curiosity and maintain learners' interest that lives in a joyful personal discovery. Teacher need to have in hand the key element, enthusiastic teaching, which influences student's outcomes. Through their respective teaching styles, teachers can contribute significantly to decrease or increase their learner's performance. The enthusiasm arose students' interest and maintain attention with positive attitude. The teaching learning process success creates potential for new mobilisation with confidence in student's achievements. These achievements encourage student's courage to try new participations proposed by their instructors. The enthusiasm should shape into adventure of knowledge in which the student is challenged to involve based on their capabilities leading to disciplined learning.

A good path to improve students learning competencies and outcomes is advocating social and emotional learning. This calms their stress and can access executive functions. The most successful class is to make sure that the learners are seated at comfortable distance from each other while organising changing groups and patterns. An individual need to be disposed to learn and ability to accept the opportunities. There is a big difference between being able to learn and having the disposition to be a learner. The learning activity becomes successful when any individual is more inclined to be engaged in a well organised activity. Being educated is a lifelong process that tends to cultivate positive learning dispositions with productive skills. The development need to be tracked and evaluated at regular intervals. A disposition is neither unique to a specific situation nor generally manifested across all situations. Dispositions may differ in their readiness and refinement. Considering such method of assessment in a developmental fashion provides a powerful handle. Systematic assessments can capture goals of good intentions that are translated into the desired 
outcomes. The challenges rely on various activities that are different from regular curriculum.

\section{Conclusion}

In this study, we reviewed literature based on improving learning capacity of students to achieve educational goals of institutions. It is observed through various studies that positive learning dispositions play important role for sustainable development in education. Researchers and educators may find our results relevant and new for applying knowledge to unfamiliar situations in teaching-learning process. Individual responsibilities can be identified and fulfilled by positive learning to achieve educational goals. Engaging in various activities, help learners to develop competencies, providing the skills to meet the required demand. This paper suggests dynamic approaches and willing to learn that significantly influence learner's nature of engagement with new opportunities. The mastery of disciplined knowledge by an explicit curriculum orient towards specific educational goals leading to selfdevelopment and self-judgement.

The defining feature of teaching-learning is that it involves change and novelty on a regular basis. In this article we discussed the importance of learning capacity with instructors' facilitations. Constructive and active process driven by actions that regulate self-learning capacity. Knowledge adoption is particular essential for institutions to function with unique competitive advantages. Students can be motivated by stimulating their curiosity to seek information in education context that makes an effective teaching practice. Measurable outcomes are achieved through research and practice environment in classrooms that describe several vital implications of education. Conceptual research of the classroom should be formed and operated within that space to signify the future practices. Motivation is a typical intellectual energy used in such activities which is a stable character of a learner. This engage the learners to achieve their educational goals. Understanding the positive learning responsibility helps the learners to foster their future endeavours. Positive learning dispositions have significant implications to design pedagogy needed to support their learning. These dispositions should be closely linked to the environment that encourages students learning. Teachers need to be able to respond and deal with changing demands in education system and students state of knowledge may act as an aid for teachers in enhancing learning. This module can be epitome for disruptive education, teaching-learning autonomy and positive learning dispositions with productive outputs.

\section{References}

1. Claxton G., Expanding the capacity to learn: A new end for education? University of Bristol Graduate School of Education, Opening Keynote Address British Educational Research Association Annual Conference, Warwick University (September 6 2006).

2. Christensen CM. Disruptive Innovation And Catalytic Change In Higher Education, Forum Futures, 43 (2008).

3. M. Assink, European Journal of Innovation Management, 9, 215 (2006).

4. M.A. Carr, G.L. Claxton, Assessment in Education, 9, 9 (2002).

5. L.G. Katz, Dispositions: definitions and implications for early childhood practices. Perspectives from ERIC/ECCE: a monograph series (Urbana, IL, ERIC Clearinghouse on ECCE) (1993).

6. D. N. Perkins, E. Jay, S. Tishman, MerrillPalmer Quarterly, 39, 1 (1993).

7. A. L. Costa, Describing the habits of mind, in: A. L. Costa \& B. Kallick (Eds) Habits of mind: discovering and exploring, Alexandria, VA, Association for Supervision and Curriculum Development, 21-40(2000).

8. Gary S. Becker, Journal of Political Economy, 70, 9 (1962).

9. Leithwood, K., Harris, A., Hopkins, D., School Leadership and Management, 28, 27 (2008).

10. Holec, H. Autonomy and Foreign Language Learning. Oxford/New York: Pergamon Press. (First Published 1979, Council of Europe) (1981).

11. Zimmerman, B. J. Motivational sources and outcomes of self-regulated learning and performance. In B. J. Zimmerman \& D. H. Schunk (Eds.), Handbook of selfregulation of learning and performance, New York: Routledge, 49 (2011).

12. McGrath, I. Teacher autonomy. In B. Sinclair, I. McGrath and T. Lamb (eds.) Learner autonomy, teacher autonomy: Future directions. 111 (London: Longman. 2000).

13. John M., Govern Lisa A., Marsch, Consciousness and Cognition, 10, 366 (2001).

14. Malle, B. F., Folk theory of mind: Conceptual foundations of human social 
cognition. In R. Hassin, J. S. Uleman \& J. A. Bargh (Eds.), the New Unconscious, New York: Oxford University Press, 225255(2005).

15. Duval, S., Wicklund, R. A. A Theory of Objective Self Awareness. New York: Academic Press (1972).

16. Simón, C., Alonso-Tapia, J., Revista de Psicodidactica, 21, 65 (2016).

17. Brouwers, A., Tomic, W, Teaching and Teacher Education, 16, 239 (2000).

18. Espelage, D., Lopes, J. Lisboa: Fundação Francisco Manuel dos Santos, 15, 467 (2017).

19. Jessica L.Grayson,Heather K.Alvarez. An International Journal of Research and Studies, 24, 1349 (2008).

20. Rolheiser, C., and J. A. Ross. "Student SelfEvaluation: What Research Says and What Practice Shows." Retrieved November 23, 2005.

21. Nunan, D., TESOL Quarterly, 29, 133 (1995).

22. Ames, C., Journal of Educational Psychology, 84, 261 (1992).

23. Toom, A., Kynäslahti, H., Krokfors, L., Jyrhämä, R., Byman, R., Stenberg, K., European Journal of Education, 45, 331 (2010).

24. Briggs, D. C., Educational Researcher, 37, 15 (2008).

25. Chatterji, M., Educational Researcher, 37, 23 (2008).

26. Confrey, J., Educational Evaluation and Policy Analysis, 28, 195 (2006).

27. Dynarski, M. Educational Researcher, 37, 27 (2008).

28. Hamersley, M. Evidence \& Policy, 1, 85 (2005).

29. Amit K., Soni. Choosing the right elearning methods: factors and elements. https://elearningindustry.com/choosingrig ht-elearning-methods-factors-elements, (2015).

30. J. D. Coie, Journal of Personality, 42 (1), 93 (1974).

31. J. Heckhausen, C. Wrosch, R. Schulz. Psychological Review, 117, 32 (2010).

32. Martin, A. J., Nejad, H. G., Colmar, S. H., Liem, G. A. D. Journal of Educational Psychology, 105, 728 (2013). 